\title{
USO DE VIRUTA DE MADERA Y LIRIO ACUÁTICO (Eichhornia crassipes) COMO AGENTES ESTRUCTURANTES EN TRATAMIENTOS AEROBIOS DE RESIDUOS HORTÍCOLAS
}

\author{
Irwing M. RAMÍREZ-SÁNCHEZ ${ }^{1}$, Ma. Elena RIOS-SOLIS ${ }^{1}$, Marcos MORALES-CONTRERAS ${ }^{1}$, \\ Francisco J. COLOMER-MENDOZA ${ }^{2,4}$, José C. VARGAS-SOTO ${ }^{3}$ y Fabián ROBLES-MARTÍNEZ ${ }^{1,4 *}$
}

\author{
${ }^{1}$ Departamento de Bioprocesos, Unidad Profesional Interdisciplinaria de Biotecnología, Instituto Politécnico \\ Nacional Av. Acueducto S/N. Col. La Laguna, Ticomán, México, 07340, D.F. México. \\ ${ }^{2}$ Departamento Ingeniería Mecánica y Construcción. Universidad Jaume I. Avda. Vicent Sos Baynat s/n, Cas- \\ tellón, C.P. 12071 (España) \\ ${ }^{3}$ Tecnología Especializada en el Medio Ambiente S.A. de C.V. México D.F., México. \\ ${ }^{4}$ REDISA, Red de Ingeniería en Saneamiento Ambiental, www.redisa.uji.es \\ *Autor para correspondencia: froblesm@ipn.mx
}

(Recibido mayo 2014; aceptado noviembre 2015)

Palabras clave: residuos sólidos, degradación aeróbica, lixiviados

\section{RESUMEN}

\begin{abstract}
En procesos aerobios para tratar residuos orgánicos con alto contenido de humedad y bajo contenido de lignina y celulosa, deben emplearse agentes estructurantes para favorecer la aireación y por lo tanto el buen desarrollo del bioproceso. En este trabajo se utilizó una mezcla de viruta de madera y lirio acuático seco (Eichhornia crassipes) como agente estructurante en diferentes porcentajes $(5,10,15$ y $20 \%)$. Cada tratamiento fue hecho por triplicado y estuvo compuesto de una mezcla que contenía los seis bioresiduos generados en mayor cantidad en la Central de Abasto de la Ciudad de México. Los experimentos se llevaron a cabo en celdas de material acrílico donde se colocó una mezcla de $1200 \mathrm{~g}$ de residuos y material estructurante. Durante el proceso, los parámetros medidos fueron el $\mathrm{pH}$, la temperatura, la densidad, el contenido de humedad, la generación de lixiviados y la reducción de masa. Los resultados mostraron que el elevado contenido de humedad de la mezcla puede ser regulado con materiales estructurantes secos, ya que estos materiales absorben parte del lixiviado durante las primeras semanas del proceso y mejoran la textura de las pilas evitando con esto que la degradación se lleve a cabo en condiciones de anaerobiosis. Tomando como base la generación de lixiviados y la reducción de masa, los mejores resultados se obtuvieron usando un $15 \%$ de agente estructurante, el cual estaba compuesto de una mezcla de 6:1 viruta de madera y lirio acuático.
\end{abstract}

Key words: solid waste, aerobic degradation, leachates

\begin{abstract}
In aerobic treatments for solid waste with high humidity content and low lignine and cellulose, bulking agents must be applied in order to improve the aeration and the performance of the process. In the present work, a mixture of wood shaving and dry water lily (Eichhornia crassipes) was tested as bulking agent at different percentages $(5,10$, 15 and $20 \%$ ). Each assay was prepared by triplicate and was composed by a mixture of
\end{abstract}


the six most important horticultural waste from a big market (Central de Abasto de la Ciudad de Mexico). The assays were run in acrylic cells where $1200 \mathrm{~g}$ of organic waste and bulking agent were mixed. During the process, $\mathrm{pH}$, temperature, density, humidity content, leachate generation and mass reduction were measured. Results showed that the high rate of humidity of this mixture could be regulated by adding dry materials. These agents absorb some leachate during the first weeks of the process and the texture in the windrow was improved avoiding the anaerobic biodegradation of this kind of waste. Evaluating the leachates generation and the mass reduction, the best results have been obtained using $15 \%$ of bulking agent, which it was composed by $6: 1$ wood shavings and dry water lily.

\section{INTRODUCCIÓN}

A nivel mundial, cada año, se pierden o se desperdician 1300 millones de toneladas de alimentos: esto equivale a la tercera parte de la comida que se produce en el mundo. En México, la incorrecta manipulación de los alimentos representa pérdidas de hasta un 20 por ciento entre el productor y el consumidor, principalmente en cereales y frutas (Anónimo 2012). Esta biomasa podría aprovecharse para obtener biogás, composta o biomasa deshidratada.

Para tratar por biosecado o por compostaje los bioresiduos que presentan un elevado nivel de humedad, como son los desechos y residuos de frutas y hortalizas, se requiere del uso de agentes estructurantes para mejorar la aireación durante el proceso. El buen desarrollo del bioproceso depende de la humedad de los residuos, biodisponibilidad de nutrientes, relación $\mathrm{C}: \mathrm{N}$, peso específico del material, porosidad y frecuencia de volteo (Oviedo et al. 2014), y cuando el bioproceso se lleva a cabo al aire libre, también influyen las condiciones ambientales locales como la humedad relativa, la velocidad del viento, radiación solar y temperatura ambiente (Turner et al. 2005).

En el caso del compostaje, la humedad debe mantenerse en un rango de 45 a $60 \%$ para favorecer la actividad microbiana (Zambra et al. 2011). Sin embargo, las frutas y verduras desechadas son utilizadas rara vez como material de proceso en las plantas de compostaje en México debido a su elevado contenido de humedad (próximos al $90 \%$ ) y a lo blando de sus tejidos por la ausencia de lignina y celulosa. Ambas características dificultan el desarrollo de un proceso aerobio debido a la generación excesiva de lixiviados durante los primeros cinco días, lo que favorece la saturación de los poros e intersticios en el interior de la pila, y en consecuencia la compactación y aumento de la densidad de la materia orgánica, favoreciendo con esto la degradación anaerobia (Robles et al. 2010), ya que cuando la humedad en las pilas sobrepasa el
$60 \%$, el agua empieza a ocupar los poros y desplaza el aire del interior de la pila (Kiely 1999).

Un agente estructurante debe proporcionar porosidad que facilite la circulación del aire al interior de la pila y absorber parte del contenido de agua de la mezcla en proceso (Iqbal et al. 2010). Diversos materiales se han probado como agentes estructurantes en el proceso de compostaje, por ejemplo, Adhikari et al. (2009) reportan haber probado mezclas de residuos de alimentos con paja de trigo, heno y viruta de madera. Por su parte Iqbal et al. (2010) probaron diversos materiales como bagazo de caña de azúcar, papel, cáscara de cacahuate y aserrín, y evaluaron la influencia de diferentes proporciones en las características físicas de la composta.

En este trabajo, la viruta de madera y el lirio acuático deshidratado (Eichhornia crassipes) fueron probados como agentes estructurantes para tratamientos aerobios de residuos orgánicos heterogéneos con elevado contenido de humedad.

\section{MATERIALES Y MÉTODOS}

\section{Muestreo de los desechos orgánicos}

Las muestras de desechos orgánicos fueron colectadas de forma separada en los contenedores ubicados en los andenes en la Central de Abasto de la Ciudad de México (CEDA). Se tomaron muestras de los seis residuos vegetales generados en mayor volumen en la CEDA (según datos proporcionados por el fideicomiso de la CEDA), los cuales fueron jitomate, plátano, papaya, naranja, piña y lechuga. En recipientes de plástico se recolectaron $3.5 \mathrm{~kg}$ de cada fruta u hortaliza para preparar los experimentos en laboratorio.

\section{Preparación del agente estructurante}

Se tomó una muestra de $10 \mathrm{~kg}$ de lirio acuático durante una operación de limpieza del lago de 
Guadalupe en el municipio de Atizapán de Zaragoza (Estado de México). El lirio acuático fue fraccionado y tamizado para obtener un tamaño de partícula de 0.5 a $1 \mathrm{~cm}$; en este mismo rango de tamaño de partícula, se encontraba también la viruta de madera. Este tamaño de partícula permitió mezclar de manera adecuada los residuos orgánicos con el material estructurante en las celdas de acrílico donde se llevó a cabo el proceso de degradación.

La viruta de madera fue obtenida de una maderería, se tamizó para obtener el mismo rango de tamaño de partícula que el lirio acuático. La viruta de madera y lirio acuático fueron secados en una estufa a $60^{\circ} \mathrm{C}$ durante 24 horas. Posteriormente, ambos materiales fueron mezclados en una proporción $\mathrm{m} / \mathrm{m}$ de $6: 1$ (dicha proporción relaciona volúmenes similares de materiales diferentes, donde el peso específico de la viruta de madera es seis veces mayor al de peso específico de lirio acuático). Esta mezcla se usó como agente estructurante.

\section{Preparación de los tratamientos}

Los experimentos se llevaron a cabo a escala de laboratorio en celdas cilíndricas de acrílico de $14.5 \mathrm{~cm}$ de diámetro, $44 \mathrm{~cm}$ de longitud y un volumen interno de $7265 \mathrm{~cm}^{3}$. En cada celda se colocaron los seis productos vegetales en igual proporción, con diferentes proporciones de la mezcla del material estructurante, de tal forma que se tuvieron 5 tratamientos con 1200 g cada uno (Cuadro I). Cada tratamiento fue hecho por triplicado y los datos reportados son promedios de éstos. Todas las celdas fueron mezcladas de forma manual durante cinco minutos diariamente, para homogenizar el contenido y facilitar la aireación de la materia orgánica. Las celdas fueron colocadas en el interior de un cubo de material acrílico, el cual contaba un extractor de aire en la parte superior para evitar que el aire al interior de las celdas se saturara de $\mathrm{CO}_{2}$ y humedad.

\section{Parámetros medidos}

Los métodos de prueba utilizados para analizar el proceso fueron los propuestos en las Normas Técnicas Mexicanas (NMX) en materia de contaminación del suelo y residuos sólidos municipales.

Durante el proceso, se monitoreó el $\mathrm{pH}$, la temperatura, la densidad, el contenido de humedad (en \%), la generación de lixiviados y la reducción de masa. Las mediciones de temperatura y del volumen de lixiviados generados se realizaron todos los días. La frecuencia de muestreo para los análisis de contenido de humedad, pérdida de masa, densidad se realizaron semanalmente.

El pH se midió utilizando un potenciómetro digital marca Conductronic ${ }^{\circledR}$. Las mediciones de temperatura se realizaron con un termómetro digital con termopar tipo K, marca Hanna Instruments ${ }^{\circledR}$, la medición se realizó en el centro de la masa de residuos de cada celda.

El contenido de humedad se determinó mediante diferencia de peso entre la muestra húmeda y la muestra seca, para esto se tomaron $10 \mathrm{~g}$ de muestra y se deshidrataron en una estufa a $60{ }^{\circ} \mathrm{C}$ durante 24 h. Para este análisis no se emplearon temperaturas más altas para no alterar las muestras, ya que la materia orgánica puede contener compuestos que a temperaturas inferiores a $100{ }^{\circ} \mathrm{C}$ puede volatilizarse,

CUADRO I. COMPOSICIÓN DE LOS TRATAMIENTOS DE MATERIA ORGÁNICA CON DIFERENTES PORCENTAJES DE MATERIAL ESTRUCTURANTE

\begin{tabular}{lrrrrr} 
& \multicolumn{5}{c}{ Masa, } \\
\hline Tratamiento & $\mathrm{A}$ & \multicolumn{1}{c}{$\mathrm{B}$} & $\mathrm{C}$ & $\mathrm{D}$ & $\mathrm{E}$ \\
\hline Proporción de & $0 \%$ & $5 \%$ & $10 \%$ & $15 \%$ & $20 \%$ \\
agente estructurante & & & & & \\
Jitomate & 200 & 190 & 180 & 170 & 160 \\
Plátano & 200 & 190 & 180 & 170 & 160 \\
Papaya & 200 & 190 & 180 & 170 & 160 \\
Naranja & 200 & 190 & 180 & 170 & 160 \\
Piña & 200 & 190 & 180 & 170 & 160 \\
Lechuga & 200 & 190 & 180 & 170 & 160 \\
Total de Mat. Orgánica & 1200 & 1140 & 1080 & 1020 & 960 \\
Total de agente estructurante & 0 & 60 & 120 & 180 & 240 \\
Total & 1200 & 1200 & 1200 & 1200 & 1200 \\
\hline
\end{tabular}

Agente estructurante: viruta de madera + lirio acuático en proporción 6:1 
como puede ser el caso de algunos alcoholes y ácidos grasos volátiles que son metabolitos secundarios en los procesos de biodegradación.

Los lixiviados generados se colectaron en charolas ubicadas en la parte inferior de las celdas que contenían los residuos hortícolas, el volumen de dicho líquido se midió diariamente en una probeta graduada de $100 \mathrm{ml}$ a las 8:00, 14:00 y 20:00 h.

Para las mediciones de redacción de masa, se pesó en una báscula de $5 \mathrm{~kg}$ de capacidad cada una de las celdas con los residuos al interior de esta, posteriormente por diferencia de peso se calculó la pérdida de masa.

\section{Tiempo de proceso}

El proceso de degradación en este trabajo se monitoreo durante 35 días, debido a que el proceso de compostaje de residuos hortícolas puede ser completado en cuatro semanas o menos tiempo si las condiciones termofilicas se mantienen, y el proceso de biosecado puede llevarse a cabo en dos semanas (Robles et al. 2012).

\section{Diseño experimental}

El diseño experimental fue por medio de análisis de varianza de un solo factor, donde se comparó el efecto del agente estructurante sobre el índice de generación de lixiviados. El diseño experimental completo (Ramírez-Sánchez 2002), no reportado aquí, comprendió la comparación de nueve ensayos de los cuales cinco son reportados en este artículo. Los estadísticos considerados fueron una certidumbre $\alpha$ del $99 \%$, distribución F y ocho grados de libertad para los tratamientos y una $f_{0.01,8,18}$. A partir de estos estadísticos y con un nivel de confianza de $99 \%$ se afirma que al utilizar una mezcla de $15 \%$ viruta y lirio en una proporción de 6:1 los lixiviados son reducidos significativamente.

\section{RESULTADOS Y DISCUSIÓN}

\section{Humedad del material en proceso}

Cuando no se utiliza agente estructurante, después de dos días de iniciado el proceso, los residuos se compactan, tomando la consistencia de un lodo, el cual resulta difícil de airear por simple volteo del material, debido a que los espacios al interior de la pila son ocupados con el agua que se libera con la ruptura de los tejidos celulares de los productos agrícolas. Esta situación trae como resultado que la degradación se lleve en condiciones de anoxia o anaerobiosis.
El empleo de lirio acuático seco como agente estructurante resulta útil para reducir la generación de lixiviados durante la primer semana de proceso. Al final del proceso de compostaje, el lirio acuático también es degradado. En lo que respecta a la viruta de madera, esta no se degradó completamente durante los 35 días del fase experimental, debido a su contenido de lignina y celulosa.

La figura 1 muestra los efectos de la adición del agente estructurante en la humedad de los residuos en degradación. En el caso donde no se utilizó agente estructurante (tratamiento A), la humedad se mantuvo en $90 \%$ durante 30 días, lo que trajo como resultado que la degradación aerobia se dificultara, debido a que los poros en el interior del material en degradación se saturaron con agua y de esta forma el aire fue desplazado, disminuyendo la difusión del aire al interior de la masa de residuos.

En los tratamientos B y C con 5 y $10 \%$ de agente estructurante, la perdida de agua no fue suficiente y la aireación se dificultó en algunas áreas trayendo consigo la generación de malos olores -indicador de la degradación anaerobia-. Es claro que la emisión de olores desagradables es un parámetro subjetivo, sin embargo no deja de ser un indicador útil del buen desarrollo del proceso en las plantas de composta. En los tratamientos C y E que contenían 10 y $20 \%$ de agente estructurante, el rango óptimo de humedad (de 45 a $60 \%$ ) se alcanzó hasta el día 35, mientras que en el tratamiento D con $15 \%$ de texturizante, la humedad optima se alcanzó después de 23 días (ver figura 1).

En los tratamientos D y E que contenían 15 y $20 \%$ de agente estructurante, se favoreció la aireación del material en proceso. La mezcla de viruta de madera y

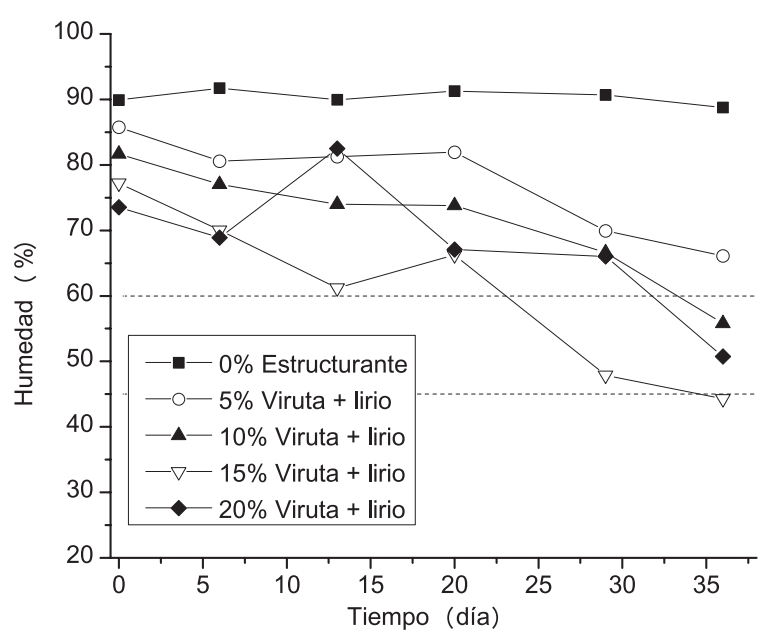

Fig. 1. Variación de humedad durante el proceso de degradación aerobia 
lirio acuático actuó de dos maneras: a) absorbió una parte del exceso de agua presente en los desechos, y b) contribuyó al aumento de la porosidad, mejorando la aireación del material y el escurrimiento del exceso de agua. Lo anterior concuerda con lo reportado por Chuang et al. (2012), en cuanto a la función del material estructurante.

Por último, se puede observar en la figura 1 que la humedad en los tratamientos E y D sufre un aparente incremento en el día 14 y 21 respectivamente, esto se debe a la heterogeneidad del material de estudio, ya que cada tratamiento está compuesto por ocho materiales con diferente contenido de humedad, lo que propicia que las muestras tomadas tengan diferentes proporciones de cada uno de los componentes de la mezcla. Sin embargo la tendencia de los gráficos es clara a pesar de estas variaciones.

\section{Reducción de masa}

Por otra parte, el rendimiento o la reducción de masa en los tratamientos aerobios, como compostaje y biosecado, dependen de la naturaleza del sustrato. En el presente trabajo, la reducción de masa en base seca para todos los tratamientos se ubicó entre 80 y $85 \%$ al final de la fase experimental, debido a la fácil biodegradación de los tejidos que forman parte de las frutas y verduras. Esto contrasta con la reducción de masa en procesos aerobios con mayor proporción de materiales lignocelulósicos, en los que la reducción de masa se encuentra alrededor del $60 \%$, como lo reporta Sauri et al. (2002). Además, tomando en cuenta la reducción de masa y la generación de lixiviados, los mejores resultados se observaron en los tratamientos con $15 \%$ de agente estructurante.

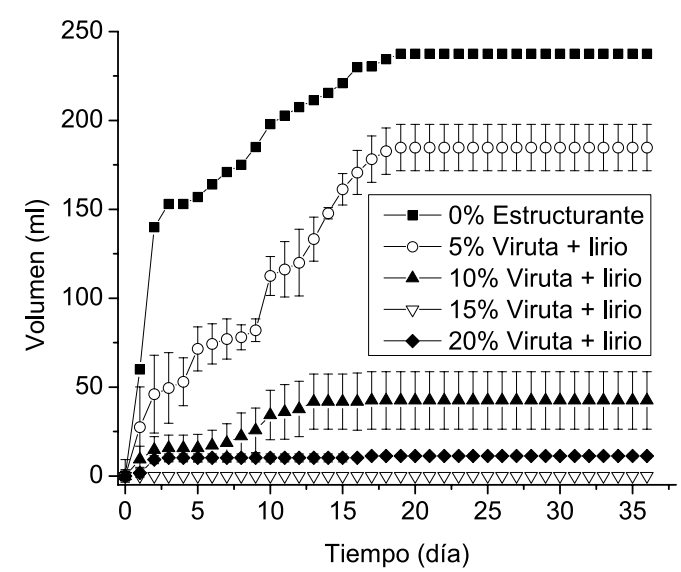

Fig. 2. Producción acumulada de lixiviados en los tratamientos

\section{Generación de lixiviados}

La viruta de madera y el lirio acuático absorbieron parte del exceso de agua. Se observó una relación directa entre la cantidad de agente estructurante usado y la disminución de los lixiviados generados en cada tratamiento, presentándose los mejores resultados con $15 \%$ de material texturizante, tratamiento donde no se generaron lixiviados. Sin embargo, esta relación ya no se mantiene si el porcentaje de material estructurante es mayor al $20 \%$, como se observa en la figura 2.

Para comparar mejor la generación de lixiviados, se manejó la relación entre el volumen de lixiviado generado durante el proceso de degradación y el volumen de agua presente inicialmente en la mezcla fresca de residuos; a esta relación se le llamó índice de generación de lixiviados (IGL) y fue calculado con la ecuación 1.

$$
I G L=\frac{\sum_{0}^{i} \text { Volumen de lixiviado diario, } \mathrm{ml}}{\text { Volumen agua de la materia orgánica inicial, } \mathrm{ml}}
$$

Con este índice se puede evaluar y estandarizar el nivel de lixiviación, aunque las celdas tengan diferentes cantidades de materia orgánica inicial. Un IGL con valor de uno se interpreta como si toda el agua contenida en la materia orgánica hubiera sido lixiviada o drenada de la celda o pila de compostaje. El valor de cero en el IGL se interpreta como la nula lixiviación, lo cual se debe, por un lado, a la absorción del agua por el AE, y por el otro, a la evaporación del agua favorecida por una buena porosidad de la pila.

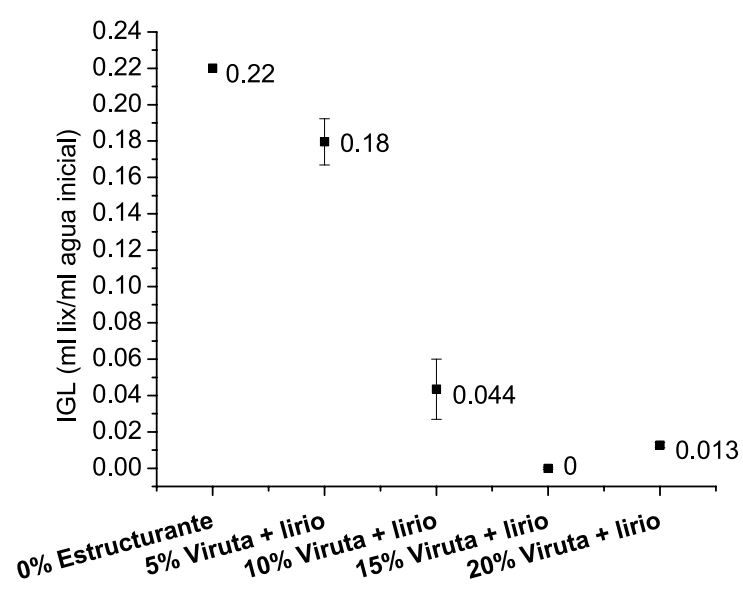

Fig. 3. Índice de generación de lixiviados en los tratamientos 
En su valor límite máximo el IGL de uno significa que la materia orgánica fue deshidratada.

La figura 3 muestra indirectamente el porcentaje total del agua lixiviada en relación con el total de agua contenida en cada tratamiento. Por ejemplo, el testigo lixivió más de $20 \%$ del agua total que contenía el residuo fresco. Sin embargo, a pesar de lo anterior este tratamiento mantuvo la humedad más alta durante el proceso, como se muestra en la figura 1. Lo anterior se explica en buena parte porque en este caso, este tratamiento inició con un contenido mayor de humedad que los tratamientos que contenían material estructurante.

\section{Temperatura del material en proceso}

En los procesos de compostaje y biosecado, la elevación de la temperatura en la matriz de los residuos es ocasionada por la generación de calor, resultado de una actividad microbiana intensa. Normalmente, este calor es retenido en el interior de la materia orgánica en proceso, dado que la materia orgánica no es buena conductora de calor. Sin embargo, en este trabajo debido a la superficie expuesta a la atmósfera en relación al pequeño volumen de residuos utilizado en cada tratamiento, la disipación de calor no permitió la consolidación de la fase termofílica. Sin embargo, la completa degradación aerobia de la materia orgánica puede llevarse a cabo independientemente de haberse alcanzado o no la fase termofílica.

El comportamiento térmico de los cinco tratamientos fue el siguiente: en los primeros dos días del proceso, la mayor temperatura registrada fue de $35^{\circ} \mathrm{C}$, esta fue disminuyendo gradualmente durante la primer semana y resto del tiempo se observó que la

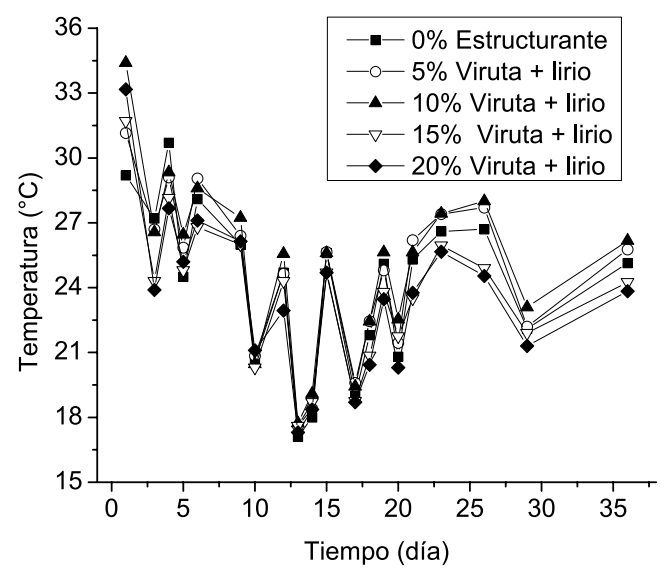

Fig. 4. Temperatura promedio de cada tratamiento durante la degradación aerobia temperatura registrada dentro de la materia orgánica era dependiente de la temperatura ambiente, la cual osciló entre 17 y $28^{\circ} \mathrm{C}$ del día 8 al 35 (figura 4).

\section{Densidad del material en proceso}

En el testigo ( $0 \%$ de material estructurante), la densidad se incrementó de 0.5 a $0.83 \mathrm{~kg} / \mathrm{dm}^{3}$ en los primeros seis días, y para el día 20, el valor de este parámetro se aproximó a $1 \mathrm{~kg} / \mathrm{dm}^{3}$. Lo anterior se debe a que la materia orgánica se va compactando por si sola conforme el proceso de degradación se desarrolla; esta situación dificulta el volteo del material, debido a que adquiere la consistencia de un lodo, lo que representa un inconveniente para mantener la aerobiosis al interior de las pilas.

La figura 5 muestra el efecto de la mezcla de viruta de madera y lirio acuático como agente estructurante para evitar la compactación de la materia orgánica durante algún tratamiento aerobio. En los tratamientos con un 15 y $20 \%$ de agente estructurante, se incrementó la porosidad de la materia orgánica, manteniéndose la densidad entre 0.2 y $0.3 \mathrm{~kg} / \mathrm{dm}^{3}$ durante todo el proceso de degradación.

\section{Evolución del pH}

Los residuos hortícolas empleados en estos experimentos presentaron un $\mathrm{pH}$ inicial ácido (entre 3 y 6). El pH de los lixiviados en todos los casos inició muy próximo a 5, para el día diez este valor ascendió a 9 como resultado de la degradación de la materia orgánica, de tal forma que los ácidos orgánicos presentes en los productos hortícolas y aquellos producidos durante el proceso de degradación (por ejemplo, ácido acético y ácido láctico)

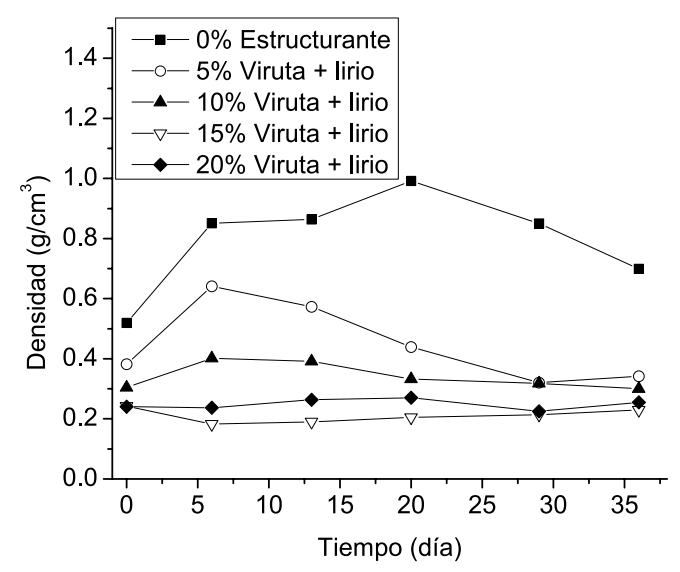

Fig. 5. Densidad promedio de cada tratamiento durante la degradación aerobia 
son metabolizados en los primeros seis días; de esta forma después de siete días el valor de $\mathrm{pH}$ se situó alrededor de 7. En el testigo (sin agente estructurante) el valor inicial de $\mathrm{pH}$ fue más bajo que el presentado en los tratamientos que contenían material estructurante, esto debe tomarse en cuenta, debido a que la combinación de altas temperaturas y $\mathrm{pH}$ bajos es un posible factor adverso en el compostaje a gran escala de residuos alimenticios como lo reporta Sundberg et al. (2004). Sobre este punto Strom (1985) reporta que los microorganismos pueden tolerar un factor medioambiental extremo, alta temperatura $o$ pH bajos, pero no ambos al mismo tiempo. Los resultados del presente trabajo muestran que el agente estructurante permitió regular el $\mathrm{pH}$ de la materia orgánica en proceso.

\section{CONCLUSIONES}

Durante el compostaje o biosecado en pilas de residuos hortícolas con alto contenido de humedad es necesaria la adición de un agente estructurante. La mezcla de viruta de madera y lirio acuático seco mejora el proceso de biodegradación debido a: i) parte del exceso de agua es absorbido por estos materiales, principalmente durante la primer semana, $\mathrm{y}$ ii) la adición del agente estructurante disminuye de la densidad de los residuos en proceso, lo que trae consigo una mayor porosidad y por lo tanto una mejor circulación del aire y un mejor drenado del excedente de agua en la matriz de residuos sólidos.

Los resultados muestran que el empleo de materiales estructurantes representa una opción para procesar las miles de toneladas generadas de residuos de alimentos, por ejemplo, residuos de centrales de abasto o grandes mercados. Además, en el caso del lirio acuático deshidratado, el encontrar aplicaciones a esta maleza acuática, puede estimular su "cosecha" y de esta forma disminuir y controlar la invasión de cuerpos de agua por esta planta.

\section{AGRADECIMIENTOS}

Los autores agradecen al Consejo Nacional de Ciencia y Tecnología (CONACYT) y al Instituto Politécnico Nacional (IPN) por el financiamiento de este proyecto y a la COFAA-IPN por el apoyo para la divulgación de los resultados de este trabajo.

\section{REFERENCIAS}

Adhikari B.J., Barrington S., Martínez J. y King S. (2009). Effectivness of three bulking agents for food waste composting. Waste Manage. 29, 197-203. http://dx.doi. org/10.1016/j.wasman.2008.04.001

Anónimo (2012). Visión del campo. (2000) Agro, Revista Industrial del Campo, Agosto-septiembre. $\mathrm{p} 5$.

Chuang M., Ding G., Tong-Bin C., Guo-Di Z. y HongTao L. (2012). Water Absorption Characteristics and Compression Strength of a New Bulking Agent. JCIT, 7(12), 20-26.

Iqbal M.K., Shafiq T. y Ahmed K. (2010). Characterization of bulking agents and its effects on physical properties of compost. Bioresour. Technol. 101, 19-1919. http:// dx.doi.org/10.1016/j.biortech.2009.10.030

Kiely G. (1999). Ingeniería Ambiental, fundamentos, entornos, tecnologías y sistemas de gestión. McGrawHill, Madrid, España, 888 pp.

Oviedo Ocana E.R., Marmolejo Rebellón L.F. y Torres Lozada P. (2014). Influencia de la frecuencia de volteo para el control de la humedad de los sustratos en el compostaje de bioresiduos de origen municipal. Rev. Int. Contam. Ambiental. 30(1), 91-100.

Ramírez-Sánchez I.M. (2002). Evaluación de materiales texturizantes en el proceso de composteo de los residuos sólidos orgánicos generados en la Central de Abastos de la Ciudad de México. Tesis de licenciatura. Unidad Profesional Interdisciplinaria de Biotecnología. Instituto Politécnico Nacional. Distrito Federal, México, 96 pp.

Robles Martínez F., Ramírez-Sánchez I.M., Piña-Guzmán A.B. y Colomer-Mendoza F.J. (2010). Efecto de la adición de agentes estructurantes a residuos hortícolas en tratamientos aerobios. Ingeniería Agrícola y Biosistemas, 2(1), 45-51.

Robles Martínez F., Silva-Rodríguez E.M., EspinosaSolares T., Piña Guzmán A.B., Calixto-Mosqueda C., Colomer Mendoza F. y Durán-Páramo E. (2012). Biodrying under Greenhouse Conditions as Pretreatment for Horticultural Waste. JEP. 3(4), 298-303. DOI: $10.4236 /$ jep.2012.34038

Sauri Riancho M.R., Nájera Aguilar H.A., Ramírez Herrera J.G. y Mejía Sánchez G.M. (2002). Aplicación del composteo como método de tratamiento de los residuos de frutas producidos en zonas de alta generación. Ingeniería, 6 (1), 13-20.

Sundberg C., Smårs S. y Jönsson H. (2004). Low pH as an inhibiting factor in the transition from mesophilic to thermophilic phase in composting. Bioresour. Technol. 95, 145-150. 
Strom P.F. (1985). Effect of temperature on bacterial species diversity in thermophilic solid-waste composting. Appl. Environ. Microbiol. 50(4), 899-905.

Turner C., Williams A., White R. y Tillet R. (2005). Inferring pathogen inactivation from the surface temperatures of compost heaps. Bioresour. Technol. 96, 521529. http://dx.doi.org/10.1016/j.biortech.2004.07.008
Zambra C.E., Moraga N.O. y Escudey M. (2011). Heat and mass transfer in unsatured porous media: Moisture effects in compost piles self-heating. Int. J. Heat Mass Transfer. 54, 2801-2810. http://dx.doi.org/10.1016/j. ijheatmasstransfer.2011.01.031 